\title{
Further Examinations of Bimodal SLD Ice Accretion in the NASA Icing Research Tunnel
}

\author{
Mark G. Potapczuk ${ }^{1}$ \\ NASA John H. Glenn Research Center, Cleveland, Ohio, 44135 USA \\ Jen-ching Tsao $^{2}$ \\ Ohio Aerospace Institute, Cleveland, Ohio, 44135 USA
}

\begin{abstract}
An ice shape database has been created to document ice accretions on a 72-inch chord NACA 23012 airfoil model resulting from an exposure to a Supercooled Large Drop (SLD) icing cloud with a bimodal drop size distribution. The ice shapes created were documented with photographs, laser scanned surface measurements over a section of the model span, and measurement of the ice mass over the same section of each accretion. The icing conditions used in the test matrix were based upon previously measured ice shapes on the same model to connect the current database to previously measured information. Ice shapes resulting from the bimodal distribution as well as from equivalent mono-modal drop size distributions were obtained and compared. Results indicate that the ice shapes resulting from the bimodal drop size distributions had higher mass and volume values than their mono-modal distribution equivalents as well as having icing limits that extended further back on the chord of the model.
\end{abstract}

\section{Introduction}

$\mathrm{I}_{\mathrm{c}}^{\mathrm{c}}$ ce accretion on aircraft surfaces as a result of exposure to supercooled large drops (SLD) is an area of continued research interest to the aerospace community. Methods for simulation of SLD conditions in ground based experimental facilities and within computational tools are currently under development at industrial, academic and governmental institutions around the world. It is clear that most experimental facilities can reproduce aspects of an SLD icing encounter and equally clear that no one facility can reproduce all aspects of an SLD icing cloud. Likewise, computational tools have been developed that can incorporate elements of SLD icing physics, but a lack of information concerning the complete range of SLD conditions limits the validation of such tools.

At the NASA Glenn Research Center, work has been underway to extend the capabilities of the Icing Research Tunnel (IRT) to include a broader range of SLD conditions. ${ }^{1}$ In addition to a broader range of conditions, the simulation of a bimodal drop size distribution representative of the freezing drizzle (FZDZ), Median Volumetric Diameter (MVD) $<40 \mu$ m distributions contained within FAA regulations ${ }^{2}$ for SLD has been developed. ${ }^{3}$ A bimodal drop size distributions is one in which there exists two peaks in liquid water content as a function of drop size. This drop-size distribution has been created in the IRT and measured to match the FAA Appendix O normalized cumulative distribution within $10 \%$ of the total volume for all drop sizes. Furthermore, those bimodal cloud development tests showed experimentally that for two different cases simulated, the measured combined drop-size distributions from two nozzle spray conditions matched the mathematical sum of the two conditions sprayed individually.

In a previous test campaign ${ }^{4}$, the authors examined the ice shapes that were produced with this bimodal distribution and compared such shapes to those formed with similar cloud conditions using single nozzle spray conditions. The resulting ice shapes were compared by evaluating cross sections of the shapes and

\footnotetext{
${ }^{1}$ Research Aerospace Engineer, Icing Branch, 21000 Brookpark Road.

${ }^{2}$ Principal Research Scientist, Icing Branch, Associate Fellow AIAA.
} 
ice shape volumes obtained from laser scan data as well as mass measurements made during the testing. This data provided some insight into the ice shape characteristics that differentiate mono-modal spray conditions from bimodal spray conditions. This in turn should enable researchers to determine whether bimodal spray icing cloud recreation is necessary for accurate reproduction of SLD icing conditions.

In this paper, additional testing of the bimodal spray condition was performed to increase the database of ice shape geometries. This was undertaken by use of an additional airfoil model. The data suggests that the trends observed in the previous study, of increased mass and volume when compared to ice shapes produced with similar mono-modal icing conditions, were found to be repeated.

\section{Facility, Model and Experimental Methods}

\section{A. Facility}

The Icing Research Tunnel is a closedloop, atmospheric tunnel, with a $1.83 \mathrm{~m}$ by 2.74 m by $6.10 \mathrm{~m}$ ( $6 \mathrm{ft}$ by $9 \mathrm{ft}$ by $20 \mathrm{ft}$ ) test section. A tunnel schematic is shown in Figure 1. The IRT's calibrated test section speed ranges between 50 and 350 knots. The test section temperature can be controlled between $+10{ }^{\circ} \mathrm{C}$ total temperature to $-35^{\circ} \mathrm{C}$ static temperature.

There are two types of spray nozzles in the IRT spray bars: the Standard nozzles that have a higher water flow rate, and the Mod1 nozzles

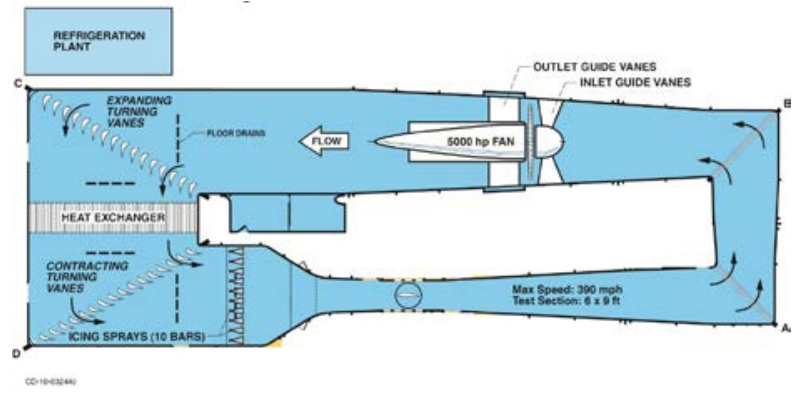

Figure 1. Schematic of the Icing Research Tunnel at NASA Glenn Research Center.

that have a lower water flow rate. Both nozzle types use internal mixing of air and water to create the cloud. The primary difference is in the diameter of the water spray tube at the nozzle exit. There are currently 165 Standard nozzles and 88 Mod1 nozzles in the spray bars. Each of the 10 bars in the spray bar system has one air manifold and two water manifolds to run the two nozzle sets. The two nozzle sets may be sprayed individually, or if they are set at the same air pressure, they may be sprayed simultaneously, with different water pressures. Nozzle air pressure (Pair) and delta pressure (expressed as water pressure minus air pressure, or DelP) and nozzle type are varied to create the desired drop size and water content. All water supplied to the IRT spray bars has been filtered and de-ionized.

Drop sizes in the IRT are typically described in terms of median volumetric diameter (MVD), which is the drop diameter at which half the liquid water content volume is contained in smaller drops (and half in larger drops). Under "normal” operating conditions, when the spray bar air pressure is 10 psig or higher, the calibrated MVD range of the spray nozzles is between 14 and $50 \mu \mathrm{m}$ for both nozzle sets. When the spray bar air pressure is set below 10 psig, larger drops can be created, resulting in a calibrated MVD as high as $270 \mu \mathrm{m}$ and maximum drop sizes as high as $1200 \mu \mathrm{m}$. This is typically only done with the Mod1 nozzles, since they have a lower flow rate, thus better matching the requirements of large-drop certification criteria. The calibrated cloud liquid water content (LWC) range of the IRT is between 0.2 and $4.5 \mathrm{~g} / \mathrm{m}^{3}$. A full report on the cloud calibration of the IRT can be found in Reference 1. 
King-Steen and Ide $^{3}$ have developed an approach to reproduce icing cloud drop size distributions that are quite close to the freezing drizzle, MVD $<40 \mu \mathrm{m}$ condition from Appendix O. Their approach is based upon simultaneous spray from both the Mod1 and Standard nozzles. By selecting a common air pressure and appropriate water pressures, drop size distributions can be created which, when combined, have a distribution which approximates the freezing drizzle, MVD $<40 \mu \mathrm{m}$ condition. The approach is described more fully in Reference 3. Figure 2 shows the two individual distributions as well as the combined distribution.

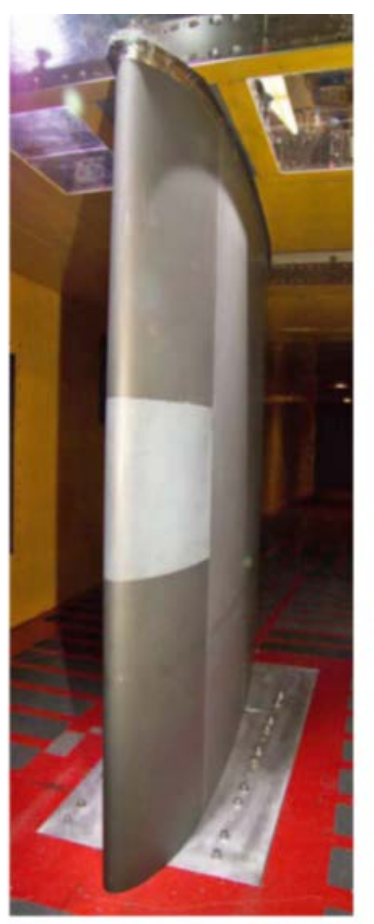

Figure 3. 72-inch chord, NACA 23012 airfoil model mounted vertically in the test section of the IRT.

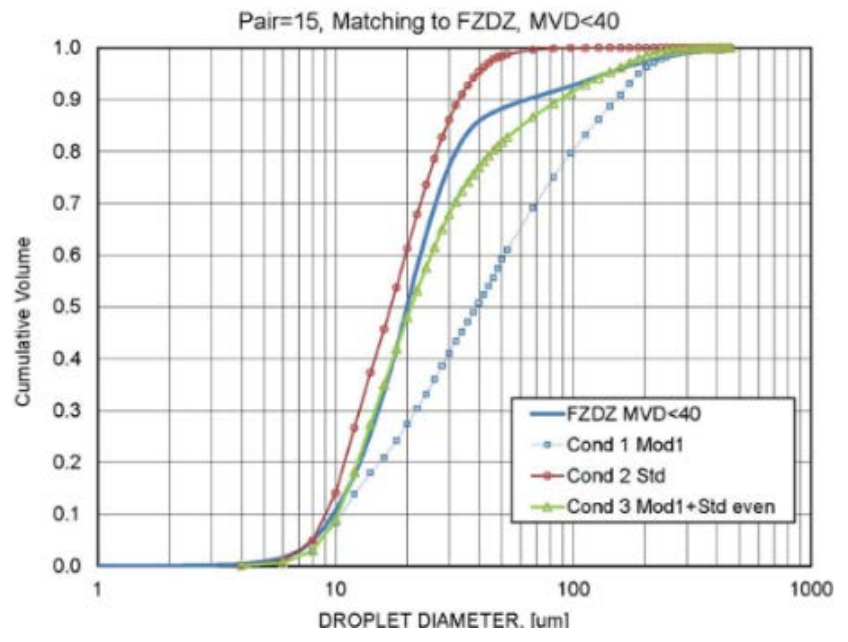

Figure 2. Normalized cumulative volume plot for data corresponding to Mod1, Standard, and combined nozzle sprays plotted alongside the Appendix 0, FZDZ, MVD $<40 \mu \mathrm{m}$ distribution.

\section{B. Model Description}

The model used in this study was a 72-inch chord NACA 23012 airfoil model. The NACA 23012 model is shown mounted in the test section of the IRT in Figure 3. The model is made of aluminum. The model was equipped with 49 pressure taps and two thermocouples were mounted to the surface. The model was mounted vertically in the tunnel on the turntable located at the center of the test section.

The pressure taps were used to determine the zero-degree angle of attack position by checking that the pressure profiles on both surfaces of the airfoil compared with published values of a NACA 23012. The thermocouple was used to evaluate when the model had come into equilibrium with the surrounding airflow.

\section{Experimental Approach}

For this study, the objective was to record and examine the ice shapes that were produced by the bimodal drop size distribution and compare that to the ice shapes produced from a similar drop size distribution that was not bimodal in nature. This was accomplished by utilizing the drop size distribution shown in Figure 2 for one set of conditions and selecting a single nozzle distribution, hereinafter called the mono-modal distribution, which had a profile close to that of the bimodal distribution. The condition selected is shown in Figure 4, which is taken from King-Steen and Ide ${ }^{3}$.

The liquid water content values for each distribution are significantly different. The bimodal distribution has a minimum LWC of $1.45 \mathrm{~g} / \mathrm{m}^{3}$ at an air speed of 250 knots while the mono-modal 


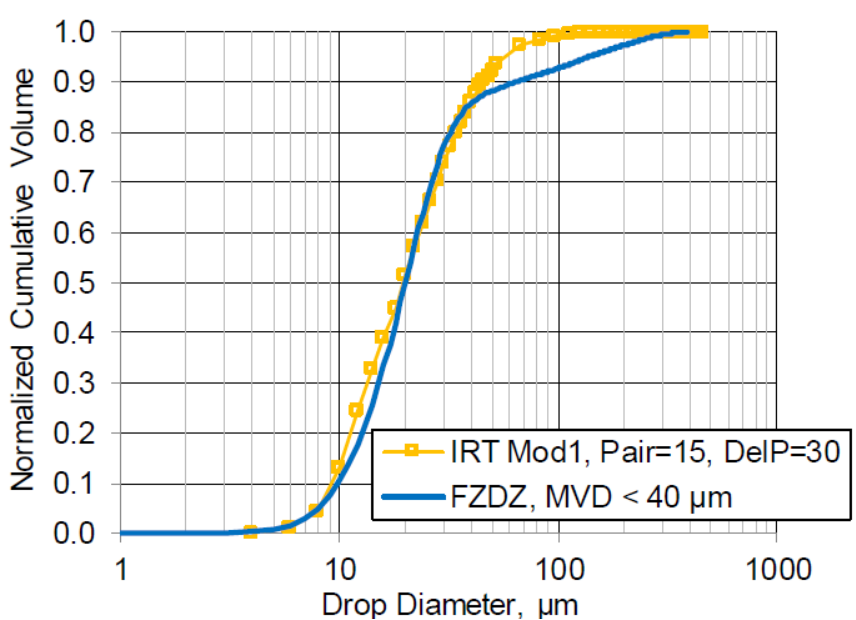

Figure 4. Normalized cumulative volume for the mono-modal drop size distribution used in this study plotted alongside the Appendix O, FZDZ, MVD $<40 \mu \mathrm{m}$ distribution.

distribution has a minimum LWC of $0.37 \mathrm{~g} / \mathrm{m}^{3}$ at the same air speed. Thus, in order to compare ice shapes of the bimodal and mono-modal distributions, icing condition scaling was required. For this study, the Olsen method ${ }^{5,6}$ was used in order to maintain the same model leading edge water accumulation size and freezing fraction for both sets of spray distributions over the range of icing conditions tested.

Each test run was conducted in the following manner. The tunnel temperature and velocity conditions were set. The spray bar air and water pressures were set. The tunnel was run at the set temperature and velocity conditions and the thermocouples on the model were monitored. When the model temperature matched the tunnel total air temperature, the model was considered to be sufficiently cold to initiate the spray. The spray was initiated and lasted for the prescribed time for the icing condition of that run.

After the spray was stopped and the tunnel velocity was reduced to idle conditions, personnel entered the test section and performed the following tasks. Photographs of the ice on the model were taken from several pre-set locations around the model. A laser scanner system was used to obtain geometric data of the ice shape using the method described by Lee, et al. ${ }^{7}$. Once the ice shapes were scanned, a 12 inch spanwise section of the ice shape was removed from the surface and weighed in order to obtain the accumulated ice mass. Following the removal of the ice mass, the model surface was cleaned of all remaining ice and prepared for the next test run.

\section{Test Conditions}

\begin{tabular}{|c|c|c|c|c|c|c|c|c|c|c|}
\hline \multirow{7}{*}{$\begin{array}{l}\text { The test } \\
\text { conditions chosen } \\
\text { were based upon } \\
\text { what could be } \\
\text { produced using the } \\
\text { bimodal drop size } \\
\text { distribution that has } \\
\text { been developed for }\end{array}$} & \multicolumn{10}{|c|}{ Test Conditions } \\
\hline & Case & Run \# & $\mid \begin{array}{c}a \\
(\operatorname{deg})\end{array}$ & $\begin{array}{c}\mathrm{V} \\
\text { (kts) }\end{array}$ & $\begin{array}{l}\text { MVD } \\
(\mu \mathrm{m})\end{array}$ & $\begin{array}{l}\text { LWC } \\
\left(\mathrm{g} / \mathrm{m}^{3}\right)\end{array}$ & $\begin{array}{c}\mathrm{T}_{\mathrm{t}} \\
\left({ }^{\circ} \mathrm{C}\right)\end{array}$ & $\begin{array}{c}\mathrm{T}_{\mathrm{s}} \\
\left({ }^{\circ} \mathrm{C}\right)\end{array}$ & $\begin{array}{l}\text { Time } \\
\text { (min) }\end{array}$ & $\mathrm{n}_{0}$ \\
\hline & EG1161 (Rime) & 1 & 2 & 150 & 30.0 & 0.55 & -22.2 & -25.2 & 10.00 & 1.17 \\
\hline & EG1164 (Horn) & 2 & 5 & 175 & 20.0 & 0.85 & -2.2 & -6.2 & 11.25 & 0.19 \\
\hline & EG1121 (Rime) & 3 & 2 & 200 & 40.0 & 0.55 & -15.6 & -20.7 & 10.00 & 0.72 \\
\hline & EG1126 (Roughness) & 4 & 2 & 200 & 20.0 & 0.50 & -2.2 & -7.4 & 2.00 & 0.27 \\
\hline & EG1129 (Horn) & 5 & 2 & 200 & 20.0 & 0.50 & -2.2 & -7.4 & 22.50 & 0.27 \\
\hline
\end{tabular}
use in the IRT and on previously tested conditions using Table 1. Reference conditions used to scale current test conditions and to evaluate the scaling capability for 72-inch chord NACA 23012 airfoil.

this model. The reference conditions from previous test programs are shown in Table 1.These reference cases were then used to scale both the mono-modal and bimodal distribution cases to be tested in this project. There were five reference cases chosen for the airfoil, however due to time constraints only a subset of cases was actually run, those corresponding to run numbers $1,2,4$, and 5 from Table 1 . The actual test conditions run during this project are shown in Tables 2 and 3. From these tables, run numbers correspond to the associated reference case and the runs marked with the letter a are the bimodal distribution version 
of that condition while those marked with the letter $\mathrm{b}$ are the mono-modal distribution versions of the reference condition.

\begin{tabular}{|c|c|c|c|c|c|c|c|c|c|c|c|c|}
\hline \multicolumn{13}{|c|}{ Test Conditions \& Results $(8 / 18 / 16)$} \\
\hline Run \# & $\begin{array}{c}\alpha \\
(\operatorname{deg})\end{array}$ & $\begin{array}{c}V \\
\text { (kts) }\end{array}$ & $\begin{array}{l}\text { MVD } \\
(\mu \mathrm{m})\end{array}$ & $\begin{array}{l}\text { LWC } \\
\left(\mathrm{g} / \mathrm{m}^{3}\right)\end{array}$ & $\begin{array}{c}\mathrm{T}_{\mathrm{t}} \\
\left({ }^{\circ} \mathrm{C}\right)\end{array}$ & $\begin{array}{c}\mathrm{T}_{\mathrm{s}} \\
\left({ }^{\circ} \mathrm{C}\right)\end{array}$ & $\begin{array}{l}\text { Time } \\
(\mathrm{min})\end{array}$ & $\mathbf{n}_{0}$ & \begin{tabular}{|c} 
Mod-1 \\
poir \\
psig
\end{tabular} & \begin{tabular}{|c} 
Mod-1 \\
$D p$, \\
psid
\end{tabular} & $\begin{array}{l}\text { Std } \\
\text { pair, } \\
\text { psig }\end{array}$ & $\begin{array}{l}\text { Std } \\
D p, \\
\text { psid }\end{array}$ \\
\hline 2.b & 5 & 175 & 19.3 & 0.45 & -0.7 & -4.8 & 21.7 & 0.19 & 15.0 & 30.0 & & \\
\hline 2.a & 5 & 175 & 20.8 & 1.77 & -4.7 & -8.7 & 5.2 & 0.19 & 15.0 & 80.0 & 15.0 & 7.0 \\
\hline 4.b & 2 & 200 & 19.3 & 0.42 & -1.4 & -6.7 & 2.42 & 0.27 & 15.0 & 30.0 & & \\
\hline 4.a & 2 & 200 & 20.8 & 1.64 & -7.3 & -12.6 & 0.59 & 0.27 & 15.0 & 80.0 & 15.0 & 7.0 \\
\hline
\end{tabular}

Table 2. Actual test conditions run for 72-inch chord NACA 23012 airfoil.

\begin{tabular}{|c|c|c|c|c|c|c|c|c|c|c|c|c|}
\hline \multicolumn{13}{|c|}{ Test Conditions \& Results $(8 / 19 / 16)$} \\
\hline Run \# & $\begin{array}{c}\alpha \\
\text { (deg) }\end{array}$ & $\begin{array}{c}V \\
\text { (kts) }\end{array}$ & $\begin{array}{l}\text { MVD } \\
(\mu \mathrm{m})\end{array}$ & $\begin{array}{l}\text { LWC } \\
\left(\mathrm{g} / \mathrm{m}^{3}\right)\end{array}$ & $\begin{array}{c}\mathrm{T}_{\mathrm{t}} \\
\left({ }^{\circ} \mathrm{C}\right)\end{array}$ & $\begin{array}{c}\mathrm{T}_{\mathrm{s}} \\
\left({ }^{\circ} \mathrm{C}\right)\end{array}$ & $\begin{array}{l}\text { Time } \\
(\min )\end{array}$ & $\mathrm{n}_{0}$ & \begin{tabular}{|c} 
Mod-1 \\
peir, \\
psig
\end{tabular} & $\begin{array}{c}\text { Mod-1 } \\
D p, \\
\text { psid }\end{array}$ & $\begin{array}{l}\text { Std } \\
p_{\text {air, }} \\
\text { psig }\end{array}$ & $\begin{array}{l}\text { Std } \\
D p \text {, } \\
\text { psid }\end{array}$ \\
\hline 5.b & 2 & 200 & 19.3 & 0.42 & -1.4 & -6.7 & 27.36 & 0.27 & 15.0 & 30.0 & & \\
\hline $5 . a$ & 2 & 200 & 20.8 & 1.64 & -7.3 & -12.6 & 6.63 & 0.27 & 15.0 & 80.0 & 15.0 & 7.0 \\
\hline 1.b & 2 & 150 & 19.3 & 0.50 & -10.2 & -13.2 & 14.8 & 0.85 & 15.0 & 30.0 & & \\
\hline 1.a & 2 & 150 & 20.8 & 1.96 & -32.1 & \begin{tabular}{|l}
-35.1 \\
\end{tabular} & 3.5 & 0.85 & 15.0 & 80.0 & 15.0 & 7.0 \\
\hline
\end{tabular}

Table 3. Actual test conditions run for 72-inch chord NACA 23012 airfoil.

Examination of the two tables shows that the freezing fraction of the tested conditions match those of the reference conditions. The duration of each spray was altered to match the impinging water accumulation parameter as proscribed by the Olsen method and the velocity values were matched from reference conditions to actual tested conditions. There is one case with a different freezing fraction when compared to the reference condition. Reference condition 1 shows a freezing fraction of 1.17 . Freezing fractions greater than 1.0 are fully rime cases and are essentially the same condition as those with freezing fractions of 1.0. The highest freezing fraction that could be run for the equivalent bimodal case was 0.85 due to the high LWC and the low temperature limit in the IRT. The resulting freezing fraction of 0.85 is close to a rime condition and thus is considered a reasonable approximation of the reference case.

\section{Results and Discussion}

Results from the experiment with some discussion are presented here. A comparison of the bimodal ice shapes to reference ice shapes obtained in this test entry is discussed as well as a comparison of monomodal and bimodal ice shapes obtained.

\section{A. Comparison to Reference Conditions}

One of the elements of this test entry was to look at comparison of the bimodal ice shapes to reference ice shapes obtained from previous testing. This was to evaluate how well the authors' methods of scaling for LWC worked for this test entry. These previous results are the reference data identified in Table 1 . The results of these comparisons is shown in Figures 5-8 below.

There are four cases for the NACA 23012 airfoil. Reference condition number 4 was a roughness case and no data is available with respect to the ice shape profile for the reference case, as the laser scanner was 
not available at that time and the previous method, ice shape tracing, was not viable for ice roughness measurements.

In Figures 5 and 6, the results of the mono-modal and bimodal conditions are compared to reference conditions 1 and 2 respectively. The results of the ice shape comparison indicate that the both cases are reasonable representations of the reference condition. This result indicates that the scaling relationship worked well for reference condition 1 despite the difference in freezing fraction mentioned previously.

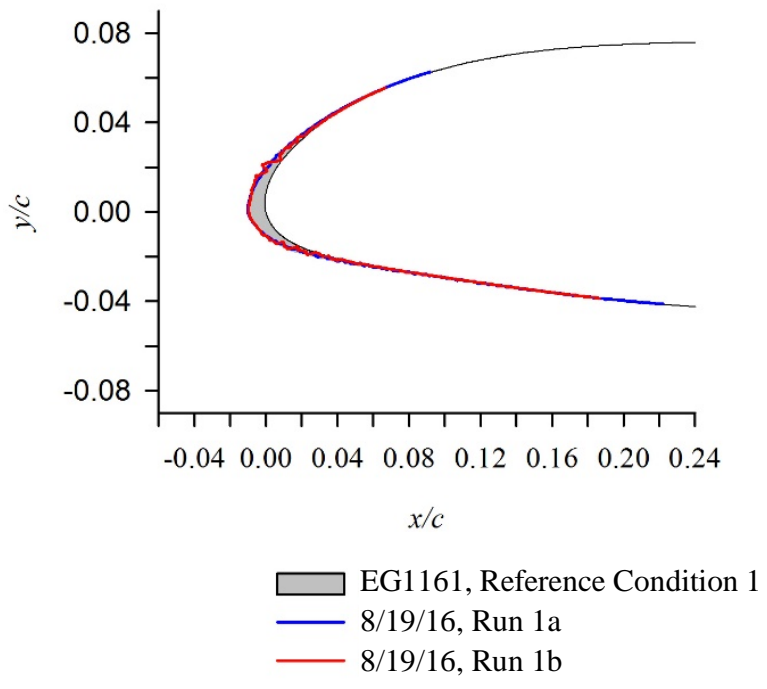

Figure 5. Mono-modal and bimodal ice shapes compared to reference condition 1 for 72-inch chord NACA 23012 airfoil.

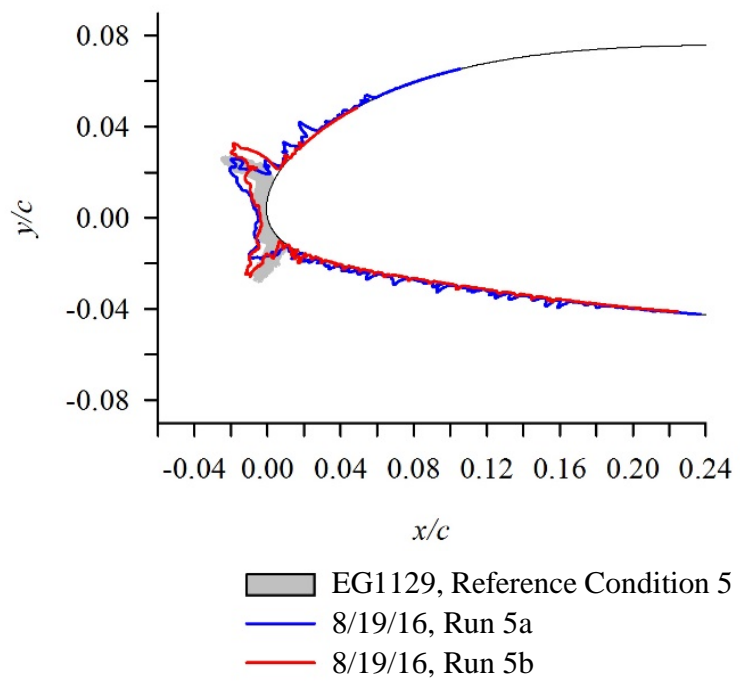

Figure 7. Mono-modal and bimodal ice shapes compared to reference condition 5 for 72-inch chord NACA 23012 airfoil.

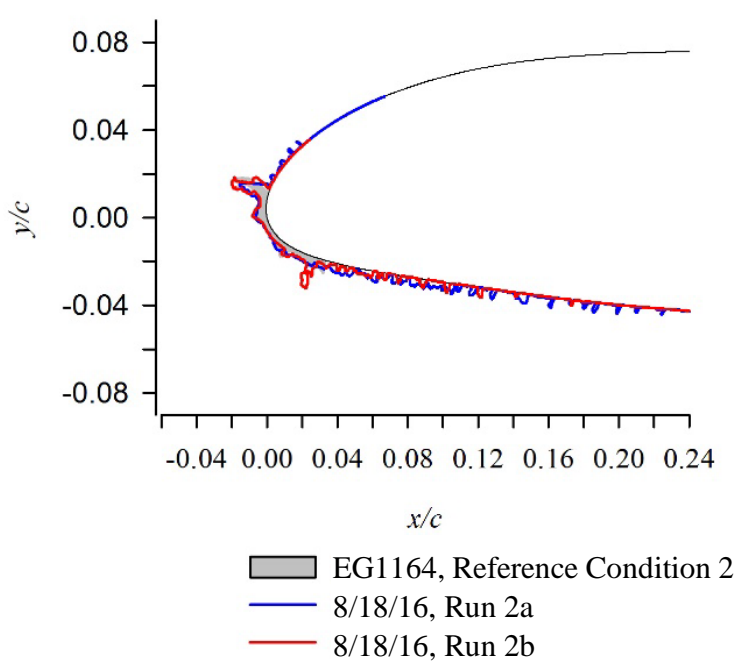

Figure 6. Mono-modal and bimodal ice shapes compared to reference condition 2 for 72-inch chord NACA 23012 airfoil.

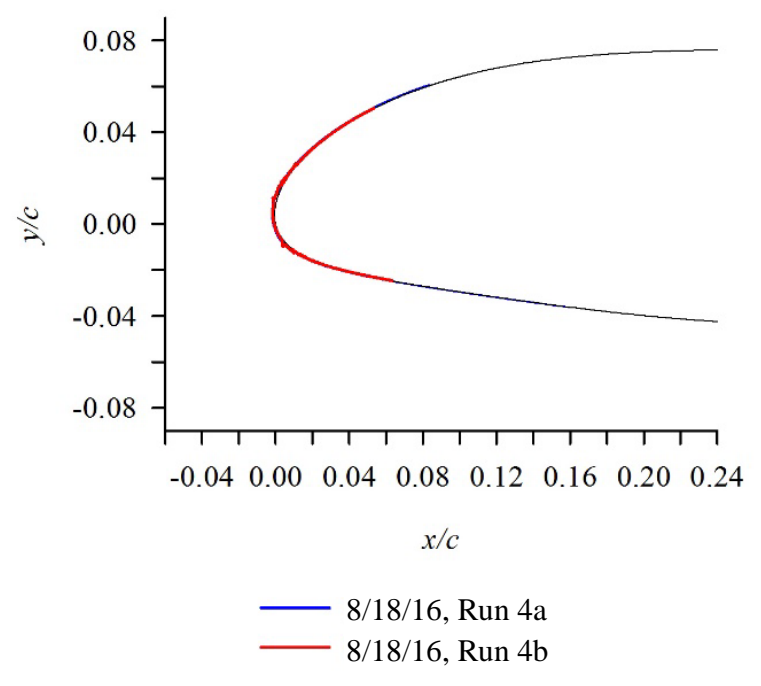

Figure 8. Mono-modal and bimodal ice shapes for condition 4 for 72-inch chord NACA 23012 airfoil. 
The ice shapes shown in Figure 7 are compared to reference condition number 5, the horn shape at a tunnel velocity of 200 knots, and seem to have the most variation. Specifically, the mono-modal ice shape, run $5 \mathrm{~b}$, seems to have the same shape as the reference condition but appears rotated in comparison to the reference case. The bimodal condition appears to have horns that are somewhat closer together than either the reference case or the mono-modal case. These differences in ice shape profile are within the variability expected when performing scaling of an icing condition.

The ice shapes for the roughness condition are compared in Figure 8. It is difficult to determine from the ice shape profiles whether or not these shapes are similar due to the lack of visual information. These results indicate the limitation of the laser scanner method in that regard.

Although difficult to tell from these images the bimodal ice shapes had icing extents that were further aft on the airfoil. This was similar to the results for the previous study. The mass contained in these further aft sections was probably small although there was no means for assessing that amount with the mass collection method used in this study. This increase in icing limits could be due to the approximately ten percent of cumulative volume contained in drop sizes larger than $100 \mu \mathrm{m}$ present in the bimodal distribution that is not found in the mono-modal distribution.

Since there were no previous bimodal icing runs with this model there was no chance to assess the repeatability of these conditions.

\section{B. Comparison of Mono-modal and Bimodal Ice Shapes}

The results of the ice shape comparison of each case to the corresponding reference cases will be discussed. Cross-sectional cuts in the scanned data corresponding to the location at the center of the span of the airfoil are shown previously in Figures 5 through 8. Each figure displays the cross sectional cut compared to the reference tracing upon which the test condition was scaled. After each icing run the mass of ice was measured in the manner described above. Additionally, the volume of ice was also determined via use of the scanned ice shape data and the capability of the Geomagic Wrap ${ }^{8}$ commercial software package to determine the volume of a closed, water-tight geometry. For the ice shapes discussed in this paper, the volume was the same 12-inch spanwise section corresponding to the ice shape removed from the model for mass measurement. Table 4 provides a summary of the measured ice mass and volume data for each run along with mass and volume differences between the mono-modal and bimodal distributions as

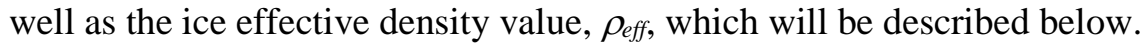

\begin{tabular}{|c|c|c|c|c|c|c|c|c|c|c|c|}
\hline \multicolumn{12}{|c|}{ Test Results } \\
\hline $\begin{array}{l}\text { Reference } \\
\text { Condition }\end{array}$ & $\begin{array}{c}\text { Mass } \\
\text { bimodal } \\
(\mathrm{g})\end{array}$ & \begin{tabular}{|c|} 
Mass \\
monomodal \\
$(\mathrm{g})$
\end{tabular} & $\begin{array}{c}\Delta \mathrm{m}_{\mathrm{i}} \\
(\mathrm{g})\end{array}$ & $\begin{array}{c}\Delta \mathrm{m}_{\mathrm{i}} \\
\%\end{array}$ & $\begin{array}{c}\text { Volume } \\
\text { bimodal } \\
\text { in }^{3}\end{array}$ & $\begin{array}{c}\text { Volume } \\
\text { monomodal } \\
\text { in }^{3}\end{array}$ & $\begin{array}{c}\Delta \text { Vol. } \\
\text { in }^{3}\end{array}$ & $\begin{array}{c}\Delta \text { Vol. } \\
\%\end{array}$ & $\begin{array}{l}\rho_{\text {eff,b }} \\
\mathrm{g} / \mathrm{in}^{3}\end{array}$ & $\begin{array}{l}\rho_{\text {eff }, m} \\
\mathrm{~g} / \mathrm{in}^{3}\end{array}$ & $\begin{array}{c}\Delta \rho_{\text {eff }} \\
\%\end{array}$ \\
\hline 1 & 349.2 & 290.2 & 59.0 & $20 \%$ & 27.68 & 24.95 & 2.73 & $11 \%$ & 12.6 & 11.6 & $8 \%$ \\
\hline 2 & 460.4 & 343.2 & 117.2 & $34 \%$ & 40.41 & 27.79 & 12.62 & $45 \%$ & 11.4 & 12.3 & $-8 \%$ \\
\hline 4 & 50.4 & 38.7 & 11.7 & $30 \%$ & 3.29 & 3.01 & 0.28 & $9 \%$ & 15.3 & 12.9 & $19 \%$ \\
\hline 5 & 606.0 & 517.1 & 88.9 & $17 \%$ & 50.21 & 44.57 & 5.64 & $13 \%$ & 12.1 & 11.6 & $4 \%$ \\
\hline
\end{tabular}

Table 4. Mass and volume measurements for the ice shapes resulting from the scaled mono-modal and bimodal distribution icing conditions from this test program. $i=i c e, b=$ bimodal, $m=$ mono-modal

The term effective density refers to the fact that this is not the physical density of the ice itself. The effective density is obtained by dividing the mass of the ice sample by the volume of the sample as obtained by the method described above. The effective density can be affected by two major elements; the amount of air trapped in the ice accretion and the fact that the scanning method, based upon its line-of-sight process, has some difficulty in documenting small concave regions of ice embedded in all ice shapes. Assuming this 
latter source of uncertainty is nominally the same for similar ice shapes, this effective density can still be used to provide a means of comparison from one ice shape to another.

For the conditions tested during this test campaign, the bimodal conditions consistently produced larger mass and volume values than the mono-modal counterparts. From the previous study with the NACA 0012 airfoil, it was determined that the repeatability for mass measurements ranged from $3.6 \%$ to $8.4 \%$ and the repeatability of the volume measurements ranged from $5.9 \%$ to $13.6 \%$. The results for mass differences between mono-modal and bimodal for these test data was significantly higher than the repeatability numbers. The results for volume differences between mono-modal and bimodal for these test data was nominally around the upper end of the repeatabilty range. The exception to this was for reference condition 2 which had a $45 \%$ increase in ice volume of the bimodal condition over the mono-modal condition. This run was the only one at a higher angle of attack which may have contributed to a larger volume as a result of icing limits further aft on the airfoil. The repeatability data was for a different airfoil so such comparisons should be considered in light of the airfoil shape differences. Unfortunately, there was not sufficient time to produce repeat runs with this airfoil and no repeatability data was obtained. Nevertheless, it would appear that the mass differential between the mono-modal results and the bimodal results are significant.

As in the results of the previous study, the effective density value for the bimodal conditions was not consistently larger or smaller than the mono-modal value. It appears that there may be differences in either how the ice shape itself develops or in how much air is trapped in the ice which at this point does not seem to be correlated to any particular characteristic of the icing clouds. For reference, the value of density for ice at $0^{\circ} \mathrm{C}$ in the units of Table 4 is $15 \mathrm{~g} / \mathrm{in}^{3}$. The results shown show that as ice shapes develop the effective density can decrease. With the exception of the roughness case, the effective density doesn't vary much between the mono-modal and bimodal ice shapes. The bimodal roughness case had the effective density closest to that of solid ice.

From the previous study, it was suggested that there may be a trend that as the airflow velocity increases the mass differences between the mono-modal and bimodal drop size distribution results seems to increase. Since each reference condition cloud has a different water mass flux, this trend is best illustrated by plotting the ice mass difference between the mono-modal and bimodal ice shapes normalized by the total water mass passing through the projected upstream area of the model. This total water mass for each run can be determined from the expression shown in Equation 1.

$$
M_{w}=L W C \cdot V \cdot t \cdot A_{p}
$$

where $L W C$ is Liquid Water Content, $V$ is airflow velocity, $t$ is exposure time, and $A_{p}$ is the projected area of the airfoil. The projected area is the projected thickness of the model times the span length used for collection of the ice mass. The span length used in all the runs for this test program was 12 inches. The projected thickness of the airfoil is dependent upon the angle of attack and was therefore $12.7 \%$ chord for the 2.0 deg conditions and 15\% chord for the 5.0 deg conditions. These values are found by rotating the airfoil to the angle of attack and finding the distance between the highest and lowest points on the surface perpendicular to the horizontal. The normalized ice mass difference is the difference in measured ice mass between the mono-modal case and the bimodal case divided by the average total water mass value for the two cases. This relationship is determined from the expression shown in Equation 2.

$$
\Delta \tilde{m}_{i}=\Delta m_{i} / \overline{M_{w}}
$$

In Figure 9, these values are plotted for the data from the previous study along with the data from this study. The previous study indicated a dependence of the ice mass difference on the tunnel airflow velocity. At the conclusion of that effort, it was suggested that more data would be useful to evaluate whether the trend would remain. It appears from this effort that the ice mass difference was independent of the airflow velocity 


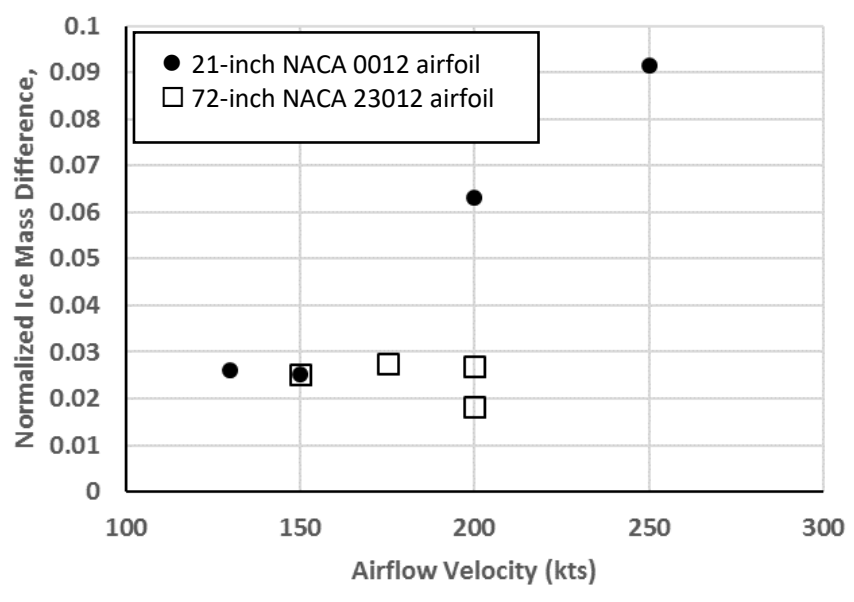

Figure 9. Difference in accumulated ice mass from mono-modal and bimodal distributions as a function of airspeed in the tunnel.

for the NACA 23012 airfoil model. Further studies are needed with more repeat runs and different airfoil models to determine if any trends appear in the results of this cloud distribution difference.

\section{Conclusion}

An initial dataset of ice shapes accreted under bimodal drop size distribution conditions in the NASA Icing Research Tunnel has been augmented with results from an additional airfoil model. A 72-inch chord NACA 23012 airfoil model was used to produce ice shapes from mono-modal and bimodal icing cloud distributions representing conditions approximating the freezing drizzle with median volumetric diameter less than 40 microns. This latter specification is one of four icing conditions specified by the Federal Aviation Administration in CFR 14, Part 25, Appendix O. The ice shapes from the bimodal clouds were compared to equivalent ice shapes from a standard IRT monomodal drop size distribution cloud where pertinent characteristics such as water impinging accumulation parameter and freezing fraction at the model leading edge were the same based upon use of the Olsen scaling method. Ice shape photographs, laser scans of the ice, and measurements of the ice mass were obtained to enable comparison of the bimodal and mono-modal distribution ice accretions.

The ice shape mass and volume measurements indicate that the trend identified in the previous study by Potapczuk, et al. ${ }^{4}$ continued for this dataset. Mass and volume measurements obtained from the bimodal runs were larger than the equivalent mono-modal conditions. These differences were compared to repeatability measurements from the previous study and mass values were found to be significantly more than the repeatability measurements. The volume measurements were at the upper range of repeatability. Since there was no directly comparable repeatability data available, additional data for this airfoil is needed to better understand the relationship between the cloud distribution differences and repeatability.

In the previous study, there did appear to be a trend in the mass difference between bimodal and monomodal distributions as a function of airspeed. This trend was not repeated during this study with this airfoil. However, there was a trend that did repeat from the previous study as there was an increase in the chordwise extent of the ice accumulation for the bimodal distribution. This could be due to the approximately ten percent of cumulative volume contained in drop sizes larger than $100 \mu \mathrm{m}$ present in the bimodal distribution that is not found in the mono-modal distribution.

Further studies and an increase in the database is needed to determine whether it is necessary to reproduce a bimodal distribution to represent freezing drizzle with an MVD less than 40 microns. Results to date indicate that the main ice shape geometries do not significantly differ. However there are differences in mass accumulation and volume which could be important for ice protection system sizing and placement.

\section{Acknowledgements}

The authors would like to thank Laura King-Steen, Judith Van Zante, Emily Timko, and Robert Ide for their expert input on the bimodal cloud conditions and how they are produced in the NASA Icing Research Tunnel. The authors would also like to thank the staff of the IRT for their assistance during preparation for

American Institute of Aeronautics and Astronautics 
testing and during test operations. This work is supported by the Aerosciences Evaluation and Test Capabilities Project.

\section{References}

${ }^{1}$ Steen, L.E., Ide, R.F., Van Zante, J.F., and Acosta, W. J., "NASA Glenn Icing Research Tunnel: 2014 and 2015 Cloud Calibration Procedure and Results,” NASA/TM—2015-218758, May 2015.

${ }^{2}$ CFR 14, Part 25, Appendix O, “Supercooled Large Drop Icing Conditions,” http://www.ecfr.gov.

${ }^{3}$ King-Steen, Laura, E. and Ide, Robert, F., "Creating a Bimodal Drop-Size Distribution in the NASA Glenn Icing Research Tunnel,” 9th AIAA Atmospheric and Space Environments Conference, AIAA AVIATION Forum, Denver, CO, June 5-8, 2017, AIAA Paper 2017-4477.

${ }^{4}$ Potapczuk, M.G., Tsao, J. and King-Steen, L.E., "Bimodal SLD Ice Accretion on a NACA 0012 Airfoil Model", 9th AIAA Atmospheric and Space Environments Conference, AIAA AVIATION Forum, Denver, CO, June 5-8, 2017, AIAA Paper 2017-4478.

${ }^{5}$ Anderson, David N., “Manual of Scaling Methods,” NASA/CR—2004-212875, March 2004.

${ }^{6}$ Anderson, D. N and Tsao, J. C., "Ice Shape Scaling for Aircraft in SLD Conditions," NASA/CR-2008-215302 and DOT/FAA/AR-07/55, September 2008

${ }^{7}$ Lee, S., Broeren, A.P., Kreeger, R.E., Potapczuk, M.G., and Utt, L., "Implementation and Validation of 3-D Ice Accretion Measurement Methodology,” AIAA 6th Atmospheric and Space Environments Conference, Atlanta, GA, June 16-20, 2014, AIAA Paper 2014-2613.

${ }^{8}$ Geomagic Wrap, http://www.geomagic.com/en/products/wrap/overview, 3D Systems Corp., April 27, 2017. 